\title{
Péter Domokos, in memoriam (1936-2014)
}

\section{Eva Toulouze}

\section{(2) OpenEdition}

Journals

Édition électronique

URL : https://journals.openedition.org/efo/4341

DOI : 10.4000/efo.4341

ISSN : 2275-1947

Éditeur

INALCO

\section{Édition imprimée}

Date de publication : 1 janvier 2014

ISBN : 978-2-343-05394-3

ISSN : 0071-2051

\section{Référence électronique}

Eva Toulouze, «Péter Domokos, in memoriam (1936-2014) », Études finno-ougriennes [En ligne], 46 | 2014, mis en ligne le 15 octobre 2015, consulté le 08 juillet 2021. URL : http:// journals.openedition.org/efo/4341; DOI : https://doi.org/10.4000/efo.4341

Ce document a été généré automatiquement le 8 juillet 2021.

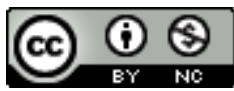

Études finno-ougriennes est mis à disposition selon les termes de la Licence Creative Commons Attribution - Pas d'Utilisation Commerciale 4.0 International. 


\section{Péter Domokos, in memoriam (1936-2014)}

\section{Eva Toulouze}

\section{Péter Domokos}

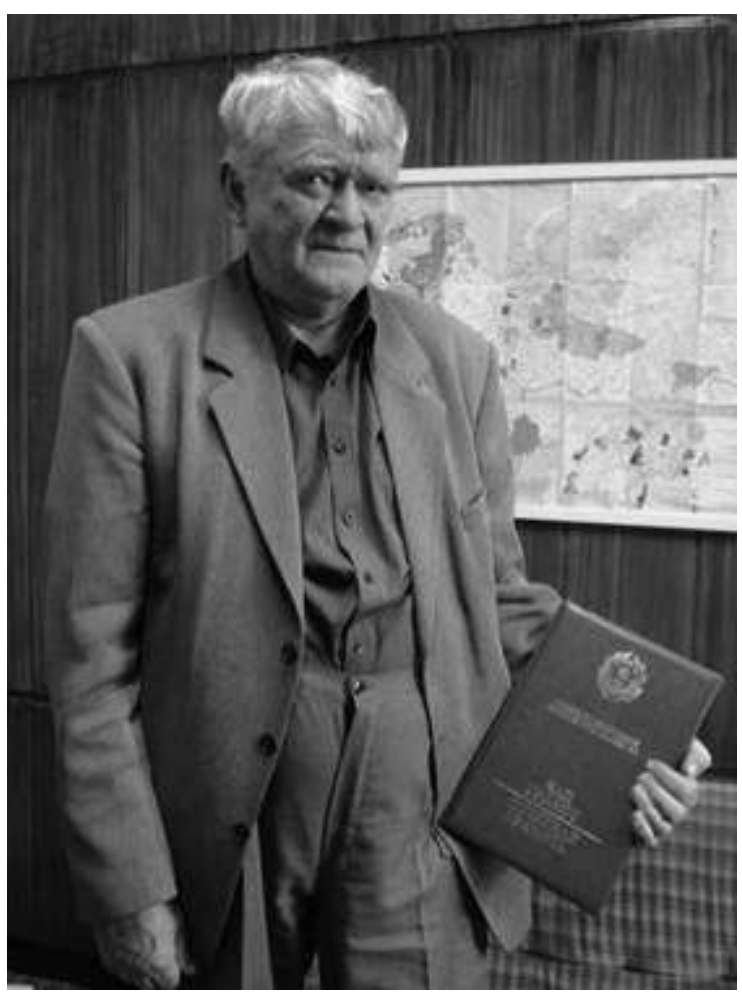

1 Péter Domokos nous a quittés le 27 mai 2014. C'était non seulement un collaborateur de notre revue, mais aussi un ami proche. Nous ne pouvions manquer de lui dédier quelques pensées dans ces pages.

2 Il était né en Transylvanie, où son père, ethnologue, folkloriste et ethnomusicologue, étudiait la culture csángó. À la fin de la guerre, la famille s'installa à Budapest, où elle 
vécut dans des conditions difficiles, le père étant contraint par le nouveau régime, au moins pour un temps, de gagner son pain dans le bâtiment. Son travail sera reconnu après 1991 et Péter Pál Domokos aura laissé une trace dans l'histoire de l'ethnologie. L'atmosphère familiale a certainement conduit Péter à s'intéresser aux humanités et à la recherche. Il choisit le domaine de la philologie hongroise.

3 Cette orientation le conduisit à une mission de lecteur de hongrois à Leningrad entre 1965 et 1970. Il y découvre en chair et en os les Finno-ougriens de Russie, ces populations dont il avait tant entendu parler au cours de ses études mais uniquement de manière abstraite. Maintenant il se fait des amis et commence à accumuler des matériaux sur les littératures de ces peuples. Il a aussi l'occasion de voyager dans des régions peu accessibles à l'époque. C'est une période de sa vie extrêmement fructueuse.

4 À son retour, il commence à travailler au département d'études finno-ougriennes de l'université de Szeged, et dix ans plus tard, il passera à l'université de Budapest. Entretemps, il élabore les matériaux accumulés, il commence à publier et il soutient sa thèse en 1973 (elle sera publiée en 19751). Il publie également, avec son collègue l'académicien Péter Hajdú ou tout seul, des outils pédagogiques sur la finnoougristique ${ }^{2}$.

5 Le sujet sur lequel il se concentre est la littérature oudmourte et sa thèse est la première étude d'envergure hors de l'Union soviétique à se pencher sur une littérature finno-ougrienne minoritaire ${ }^{3}$. Sa soutenance et surtout sa publication ont soulevé des vagues en Oudmourtie. Si à la lecture de l'œuvre aujourd'hui on est plutôt impressionné par son insertion dans le cadre idéologique de l'époque et par ses références, obligées bien sûr, au marxisme-léninisme, elle apparaissait en URSS comme autrement frondeuse. Le Comité central du parti oudmourte en a organisé la traduction et l'a discutée dans une séance spéciale. Les principaux points sur lesquels cette histoire hongroise de la littérature oudmourte allait à l'encontre du discours officiel étaient au nombre de deux. Tout d'abord, Domokos s'inscrivait en faux contre l'idée canonique que la littérature oudmourte, comme les autres littératures des peuples minoritaires de Russie, était « enfant d'octobre » : pour le discours officiel, il n'existait rien avant la politique soviétique des nationalités, et la littérature oudmourte était née dans les années 1920 dans un vide absolu. Or Domokos consacrait une partie consistante de son œuvre à ce qui précède l'ère soviétique, montrant que les missionnaires avaient jalonné le terrain et permis la constitution d'un outil qui, à l'épreuve du feu des décisions qui suivent le changement de pouvoir, s'avérera performant. La deuxième question qui fâche concerne le chef de file des écrivains oudmourtes des années 1920, Kuzebaj Gerd. Celui-ci, qui avait condamné lors du procès de 1933-34 et été fusillé le $1^{\text {er }}$ novembre 1937 alors qu'il était prisonnier aux îles Solovki, venait tout juste d'être réhabilité à grand peine au moment de la soutenance de la thèse. Péter Domokos le présente, sans complexes, comme la grande figure de la littérature oudmourte sans s'attarder sur ses «erreurs politiques». Son principal informateur sur Gerd, Foma Kuzmič Ermakov, sera exclu du parti. Si pour ce livre Domokos acquiert alors en Oudmourtie une réputation pour le moins ambiguë, après 1991 il sera considéré comme un précurseur et presque comme un héros national.

6 C'est en 1984 que Péter Domokos soutient sa thèse de doctorat d'État. Il la consacre aux littératures finno-ougriennes de Russie, dont il met en évidence similitudes et différences. Elle débouche sur un livre, La formation des littératures des petits peuples ouraliens ${ }^{4}$. Celui-ci, de même que l'histoire de la littérature oudmourte, sera traduit en 
russe et publiés. Ces traductions ont sérieusement déplu à Péter Domokos, car elles déformaient sa pensée en la simplifiant à l'extrême, mais en même temps elles ont fait connaître ses thèses à un public autrement plus large que celui des lecteurs en langue hongroise.

7 S'en suit une période éprouvante pour le chercheur. Il est le plus "gradé » de la chaire d'études finno-ougriennes de l'université de Budapest, ELTE. C'est lui qui devrait théoriquement en devenir le responsable. Mais cette perspective suscite une polémique qui devient internationale : comment un non-linguiste pourrait-il diriger une chaire d'études finno-ougriennes? Alors même que la discipline se diversifie, les linguistes, faute d'avoir désormais le monopole, prétendent à la prééminence. Il est vrai que le terme finno-ougrien par lui-même renvoie à des réalités linguistiques...

8 Toujours est-il que cette polémique devient un combat de personnes, au centre duquel Domokos n'a pas manqué de prendre des coups très durs. La principale victime, bien sûr, est la chaire d'études finno-ougriennes de Budapest elle-même, qui sera déchirée pendant près de huit ans. En 1992 finalement Domokos en prendra la responsabilité pour plus d'une décennie et il aura fort à faire à raccommoder le tissu profondément déchiré. Mais il y arrivera, laissant à son successeur Ferenc Havas une chaire désormais sereine et en bonne santé.

9 Son apport fondamental a été d'instituer dans le domaine de la finno-ougristique une nouvelle discipline : les études littéraires. Il est venu au bon moment : la Russie s'était suffisamment ouverte pour que les documents, les œuvres originales, soient enfin relativement accessibles à un chercheur étranger, et par ailleurs suffisamment de temps avait passé pour que les périodes de ces littératures qui avaient été cachées ou niées totalement - je fais référence aux années 1920-30, mises à l'index jusqu'à l'approche des années 1960 - refassent surface. Il fallait bien reconnaître désormais que ces langues, jusqu'alors étudiées dans les universités de Hongrie en tant que langues de folklore, avaient permis l'éclosion d'une culture écrite et qu'elles pouvaient être approchées en tant qu'outil d'expression moderne, standardisé, fonctionnel. En écrivant sur elles, en nous faisant connaître leur histoire littéraire, Péter Domokos leur a donné une place parmi les cultures modernes, nous a encouragés à les traiter comme des cultures vivantes, à leur donner la dignité de cultures vivantes.

Il a laissé des disciples - sans doute moins qu'il aurait pu, s'il avait pu se consacrer à transmettre son savoir plus qu'à panser un corps meurtri - Katalin Nagy, Virág Dyekiss, Gábor Tillinger. Sans que le lien soit aussi direct, on peut considérer que les travaux de Johanna Domokos, mais aussi les miens, relèvent d'une même inspiration.

11 Péter Domokos a été un novateur et, comme c'est souvent le cas, il a été longtemps incompris. Aujourd'hui, cependant, personne ne met plus en doute la légitimité de l'étude des littératures finno-ougriennes et c'est là quelque chose que nous lui devons. 


\section{NOTES}

1. En hongrois : Az udmurt irodalom története, Budapest : Akadémiai Kiadó, 1975.

2. En hongrois: Uralisztikai olvasókönyv Budapest: Akadémiai Kiadó, 1977; Uráli nyelvrokonaink (Hajdú Péter társszerzővel). Bp., Tankönyvkiadó, 1978.

3. Du moins la première œuvre publiée. Domokos évoquait toujours la thèse de l'Anglais John Coates sur la littérature komie qui l'avait précédé, mais qui n'a jamais été publiée.

4. En hongrois : A kisebb uráli népek irodalmának kialakulása, Budapest : Akadémiai Kiadó, 1985.

5. En russe: ИСТОРИЯ УДМУРТСКОЙ ЛИТЕРАТУРЫ, ИЖЕВСК, 1993; ФОРМИРОВАНИЕ ЛИТЕРАТУР МАЛЫХ УРАЛЬСКИХ НАРОДОВ, ЙОШКАР ОЛА, 1993. 